\title{
Oficina sobreTerritório: um estudo sobre os Areais de Itaguaí
}

\author{
Beatriz Carneiro \\ Aluna do Departamento de Arquitetura e Urbanismo da PUC-Rio. \\ Contato: beatrizmvcarneiro@gmail.com
}

RESUMO

O presente artigo visa documentar a oficina sobre território, ocorrida em 2018 como iniciativa do grupo de discentes organizadores da nona edição da Semana de Arquitetura da PUC-Rio e jovens arquitetos brasileiros. O estudo coletivo teve como principal intuito entender e propor intervençôes na área dos Areais de Itaguaí, de onde é extraída a areia utilizada pela construção civil carioca.

Palavras-chave: arquitetura; semana de arquitetura; oficina; areais; itaguaí; construção civil; território

\section{ABSTRACT}

This article aims to document the workshop sobre território that happened in 2018 as an initiative by the group of student who organized the ninth edition of the Architecture Week of PUC-Rio and young Brazilian architects. The main purpose of the study was to understand and propose interventions in the area of Itaguaís Dunes, where sand mining exploration for civil construction in Rio de Janeiro take place.

Key-words: architecture; architecture week; workshop; itaguaí; civil construction; territory 


\section{A Semana de Arquitetura}

Iniciada em 2006, a Semana de Arquitetura da PUC-Rio - intitulada Ser Urbano - acontece anualmente com a reuniáo de alunas e alunos de diferentes períodos do curso interessados em propor discussóes acerca do campo da arquitetura. Desde sua criação, o Ser Urbano explora a partir de um espectro interdisciplinar o debate da teoria e do projeto em mesas de discussão, palestras, exibição de filmes e montagem de pavilhôes, dentre outras ações. A principal intenção é suscitar, através da conjugação de diferentes falas e opiniôes dos convidados (internos e externos ao departamento), um pensamento crítico sobre a questão que está sendo abordada na edição.

Para o ano de 2018, foi proposta a temática do território, tendo em vista as complexidades e tensóes que envolvem esse assunto, sobretudo em ano de eleiçôes presidenciais. A partir do destrinchamento do conceito de território, com falas de arquitetos, sociólogos, jornalistas, ativistas sociais e artistas plásticos, os estudantes propuseram o mapeamento de questóes que giram em torno da sua condição contemporânea, como lugar de fala, discurso de ódio e espaços de repressão (Figura 1).

Além disso, foi proposto também pela comissão de alunos dessa edição, em conjunto com jovens arquitetos - ex-alunos da PUC-Rio e pioneiros do Ser Urbano - , uma oficina que se debruçasse sobre os Areais de Itaguaí, Região Metropolitana do Rio de Janeiro, principal área de onde é extraída a areia utilizada na construção civil carioca.

Neste sentido, o ensaio visa documentar o trabalho desenvolvido durante a oficina e as discussões levantadas durante os dias de imersão no assunto. $\mathrm{O}$ desenvolvimento da oficina como produção de conhe-

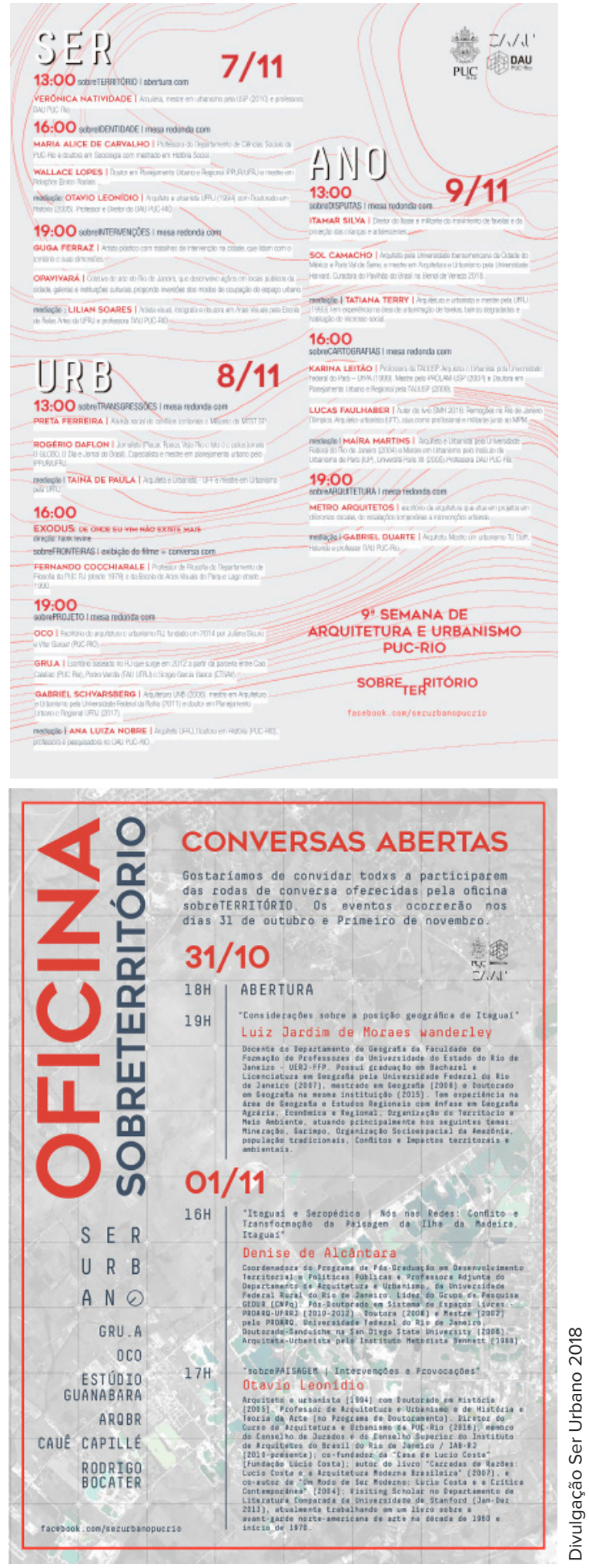

Programação do Ser Urbano 2018 com o tema sobreterritório. 
cimento pode, dessa forma, se tornar parte de um amplo escopo de pesquisa sobre os Areais de Itaguaí, como experiência experimental e acadêmica.

\section{Referencial Teórico}

Para o estudo dos Areais de Itaguaí, a oficina sobre território aconteceu como um workshop de quatro dias no campus da PUC, uma semana antes ao Ser Urbano 2018. Durante esse período, os estudantes participantes - tanto internos da PUC quanto de outras faculdades de Arquitetura e Urbanismo do Rio de Janeiro - se reuniram em quatro grupos de cinco pessoas somadas a dois ou três arquitetos para proporem e apresentarem um projeto para a área, repensando o papel da construçáo civil, tendo em vista a extração de uma das suas principais matérias-primas: a areia que se tornará concreto e reboco.

A programação foi iniciada com falas de inserção abertas a todos os ouvintes interessados sobre a questão. Foram convidados o professor de Geografia da UERJ (Universidade Estadual do Rio de Janeiro) Luiz Jardim de Moraes Wanderley, cuja fala intitulada "Consideraçôes sobre a posição geográfica de Itaguaî” localizou problemáticas da regiáo a partir de suas atividades de extração e de formação de cidade; a professora de Arquitetura da UFRRJ (Universidade Federal Rural do Rio de Janeiro) Denise de Alcântara que apresentou sua pesquisa acadêmica "Nós nas redes: Conflito e Transformação da Paisagem da Ilha da Madeira, Itaguaî" sobre o crime ambiental produzido pela atividade extrativista; e o professor e diretor do DAU (Departamento de Arquitetura e Urbanismo da PUC-Rio) Otavio Leonídio com a fala "sobre paisagem: Inter- vençôes e Provocações" que instigou os participantes pela busca de um projeto crítico-teórico nas suas produçóes.

Continuada a programaçáo, alunos e arquitetos visitaram o Areal do Futuro, um dos tantos que compóem a extração de areia de Itaguaí, guiados pelo seu proprietário. No local, os envolvidos puderam entender um pouco sobre a complexa paisagem decorrente da atividade, sua ocupaçáo no espaço e como se dá o processo de trabalho. Foi possível, dessa forma, elucidar o percurso da areia, desde sua extração até seu convencional contato com a profissáo do arquiteto: a obra.

A visita permitiu ainda a identificação do contexto geo-espacial dos areais: cada propriedade extrativista é privada e ocupa largas metragens quadradas, onde são abertas piscinas — dada a sua localização sobre o aquífero Piranema, que abastece parte do Rio de Janeiro - para a implantaçáo de máquinas que bombeiam a areia e despejam ali um subproduto da extração: o sulfato de alumínio. O cenário de águas cristalinas é desmistificado pela sua severa poluição e pelo consequente comprometimento do lençol freático da área. Além disso, o eventual esgotamento dessas piscinas gera a necessidade de abertura de novas fendas, numa contínua apropriação e recorte do espaço, enquanto as lagoas desativadas se transformam em áreas de lazer e, até mesmo, em cenário para a filmagem de novelas.

É ainda característica da atividade a mão de obra escassa necessária para sua realização. Em torno de cinco homens manipulam as poucas máquinas que ocupam vastas paisagens e fornecem diretamente para 
caminhôes da construção civil a areia extraída, também geralmente controlados pelo sexo masculino. A mínima densidade demográfica e a total ausência de mulheres coloca em questáo as condiçóes daquele trabalho que é ainda problematizado pelo expresso desejo do proprietário de desativação de parte do seu areal para a construção de um conjunto habitacional no local.

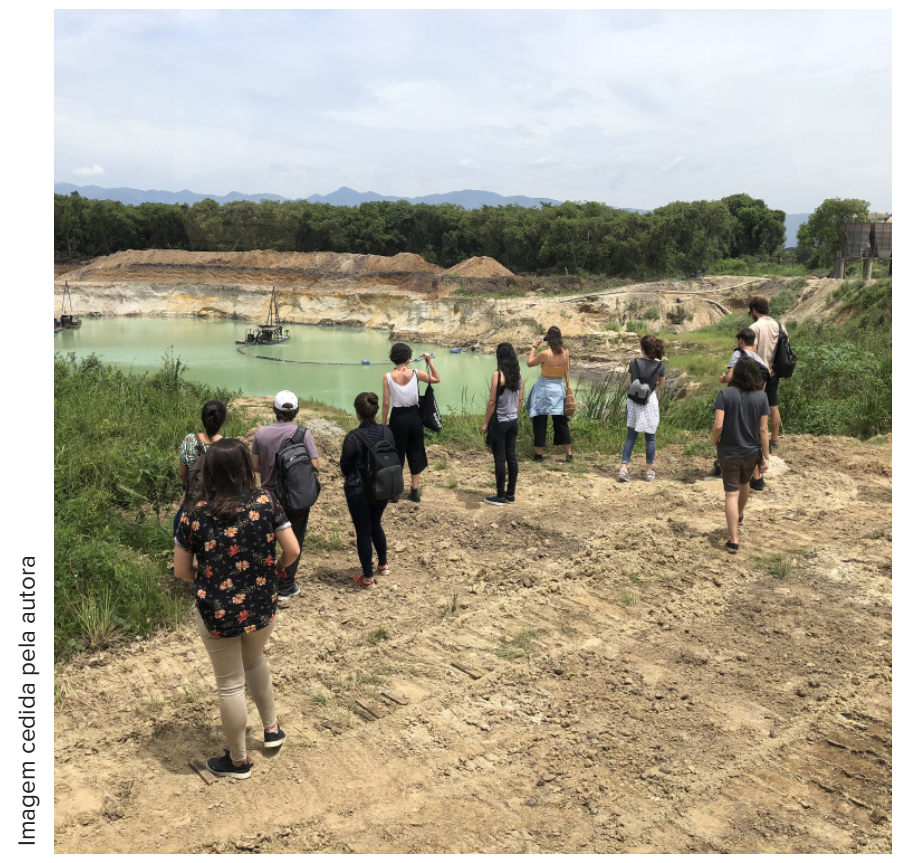

Visita ao Areal do Futuro, Itaguai. Novembro de 2018.

\section{As propostas}

As propostas desenvolvidas pelos quatro grupos divergiram em escala e enfoque da problemática do território, tendo sempre em vista a arquitetura como um dos combustíveis geradores do sistema explorado.

O primeiro grupo ${ }^{1}$ fez uma pesquisa sobre a presença, ainda que implícita, da areia ali extraída nos contextos industriais, econômicos, sociais e infraestruturais de Itaguaí e Seropédica. Foi descoberto, com isso, o caráter oculto desse substrato nos problemas por ele gerados como atividade extrativista, tanto na atuação de milícias que controlam muitos desses areais, quanto nos impactos na paisagem e na saúde da população. Tal análise embasou a proposta de elucidar todas as nuances que compóem o exercício de extração, em especial a violência nela inserida, através da implantação de uma correia transportadora de larga escala.

A esteira proposta seria capaz de conduzir não apenas a areia como substrato, mas principalmente como produto de um sistema velado e complexo, a qualquer lugar do planeta. $\mathrm{O}$ objeto de transporte personifica o anonimato das pessoas que fazem parte desse sistema e do percurso da areia que pouco se sabe de onde vem e para onde vai. Em paralelo ao projeto que acusa esse controle oculto da extração, uma análise do sociólogo Roland Barthes: "De um lado, a matéria bruta, telúrica, e, de outro, o objeto perfeito, humano; e, entre esses dois extremos, nada: apenas o trajeto vigiado(...)" (BARTHES, 2006 apud WISNIK, 2018, p. 37), sobre a importância do trajeto altamente vigiado e suprimido para que o produto final continue sendo consumido.

A partir de outra abordagem, o segundo grupo ${ }^{2}$ destrinchou a previsão de construçáo de um conjunto habitacional do programa Minha Casa, Minha Vida em parte do areal já saturado pela extração. A questáo principal girou em torno de como a escala humana cotidiana poderia se dar, a partir da arquitetura, num espaço sensivelmente árido e com a evidente pressão imobiliária sobre áreas periféricas pouco propícias à construção. Por isso alicerçado, foi iniciada uma pesquisa sobre o cenário mutável do local com a contínua abertura e fechamento de lagoas e o cruzamento desses recortes crescentes com a possível implantação do programa. O grupo especulou, com 


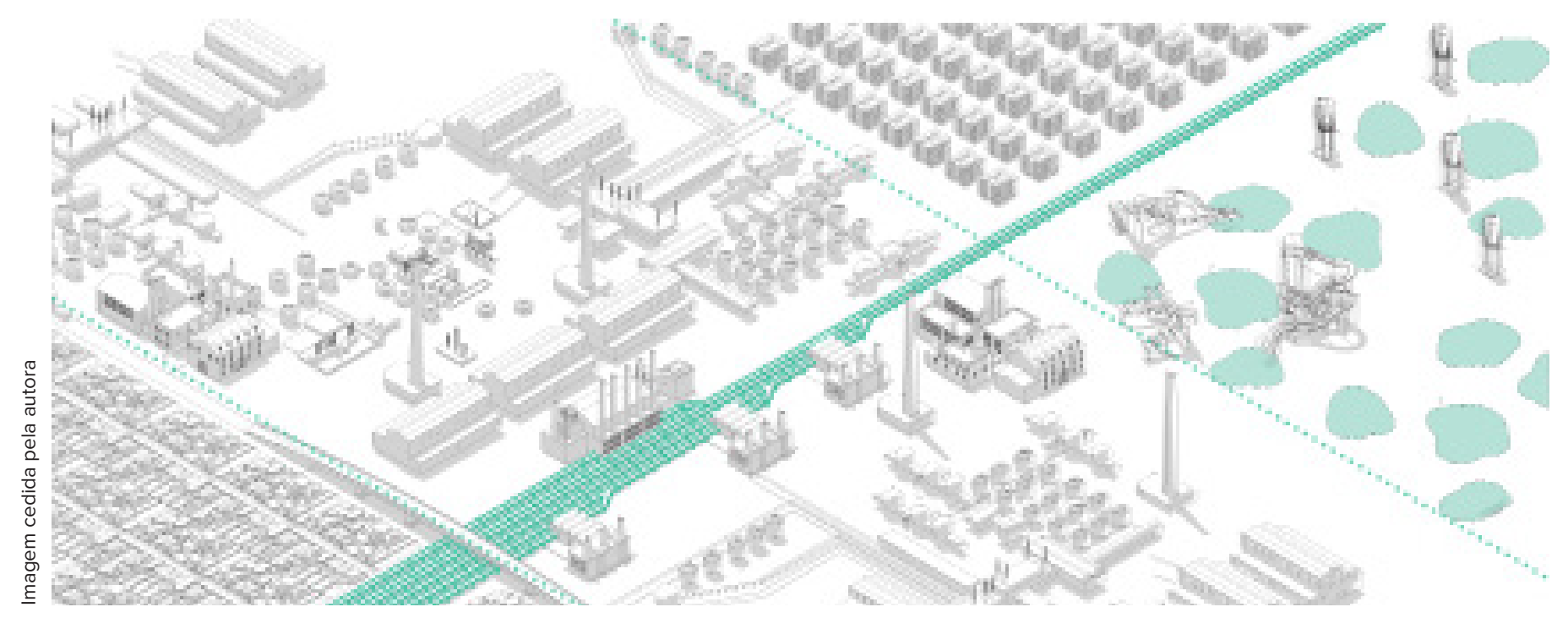

Perspectiva isométrica do cenário proposto, produzida pelo Grupo 1.

isso, um componente arquitetônico composto por módulos que ocupam a paisagem de forma aleatória e incessante, assim como fazem as piscinas. De fato, a premissa do "edifício" é a perseguição pelas carcaças das máquinas de extração abandonadas após o desativamento dessas fendas.

Como arquitetura, o sistema acontece em altura, o que garante a permanência da paisagem, cada vez mais caótica, dada a continuidade da extração de areia. Consequentemente, conserva-se a possibilidade de construção do próprio componente arquitetônico, personificando o ciclo vicioso presente na relação entre demanda e extração. Além disso, a estrutura proposta não passa por um processo de especificação de usos ou fachadas, questionando a produção genérica de cidade hoje, em especial no caso de conjuntos habitacionais de programas governamentais.

Já o terceiro grupo ${ }^{3}$ explorou a atmosfera do local, entendendo a ausência de referências, escala e de uma memória coletiva, identificada somente pela presença do seu maquinário perene e dos veículos que realizam a retirada da matéria-prima. A partir disso, foi criada uma narrativa baseada na expansão do areal para toda a região que, entáo, é murado e transformado numa espécie de parque ecológico.

Em diálogo com o fato de que eventualmente os areais são cenário para a filmagem de novelas pela sua paisagem "paradisíaca", o grupo propôs a construção do parque como um espetáculo distópico que potencializa a relaçáo de servidáo entre a regiáo metropolitana e a metrópole através do turismo. Dessa forma, é representado o turismo do capital, cuja relação pouco questiona o abandono público-social típico de áreas periféricas que se tornam cenários do entretenimento. Ou ainda, o desconhecimento sobre os tantos processos, muitas vezes cruéis e violentos, que geram os produtos finais que chegam à metrópole incólumes.

Por fim, o quarto grupo ${ }^{4}$ explorou a relação de positivo-negativo entre a atividade extrativista e a construção civil, tendo em vista os consequentes binômios por ela gerados. Foi proposto um contexto em que o processo de extração da areia produz, no mesmo espaço-tempo, um edifício genérico, espacializando 


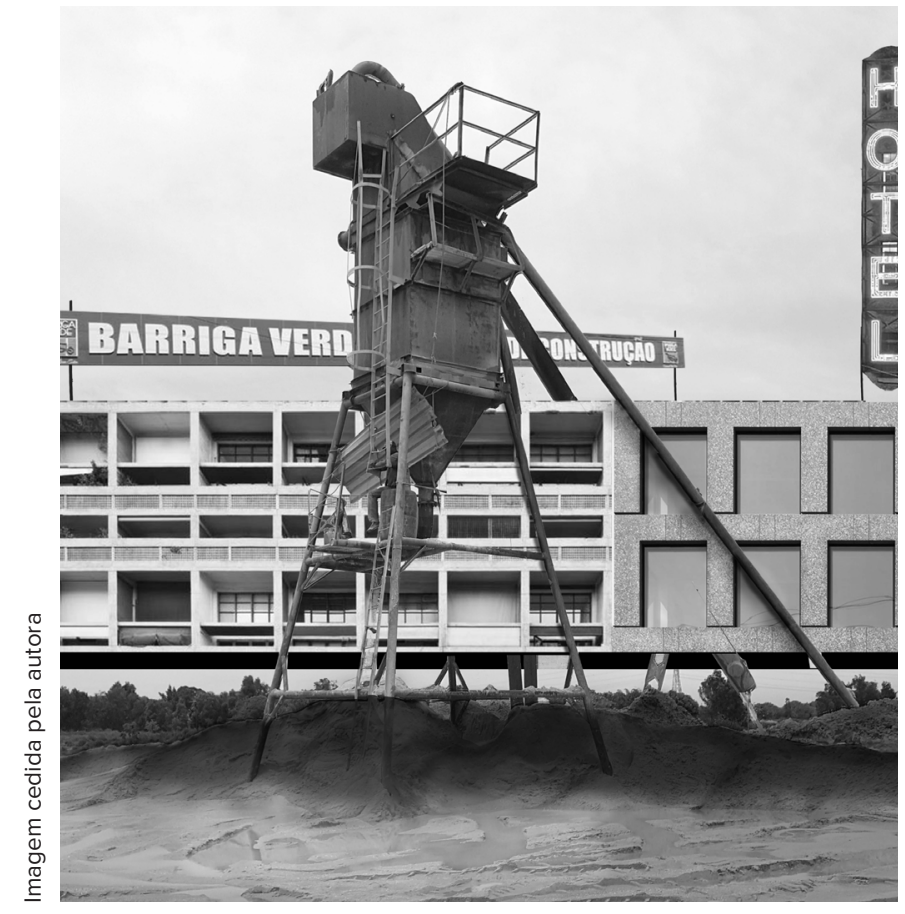

Colagem com a proposta de intervenção, produzida pelo Grupo 2.

as incongruências identificadas. Para cada montante de terra retirado, um proporcional montante de cidade é gerado, dado o contínuo ciclo entre a falácia da infinitude do recurso natural - e da incompreensão sobre os processos que cercam a extração - e as ininterruptas demandas de um tecido urbano permanentemente sedento por mais ocupação.

A busca pelo desvelamento do sistema, através da própria arquitetura, coloca a areia como matriz condicionante da produção urbana, instantaneamente espacializada como produto final através do concreto. Não somente isso, o projeto também coloca em questão o modus operandi da relação humana com o meio-ambiente e o território, reduzidos a meros recursos para o já inflado crescimento urbano, em especial sob a ótica dos arquitetos que são agentes de transformação da cidade.

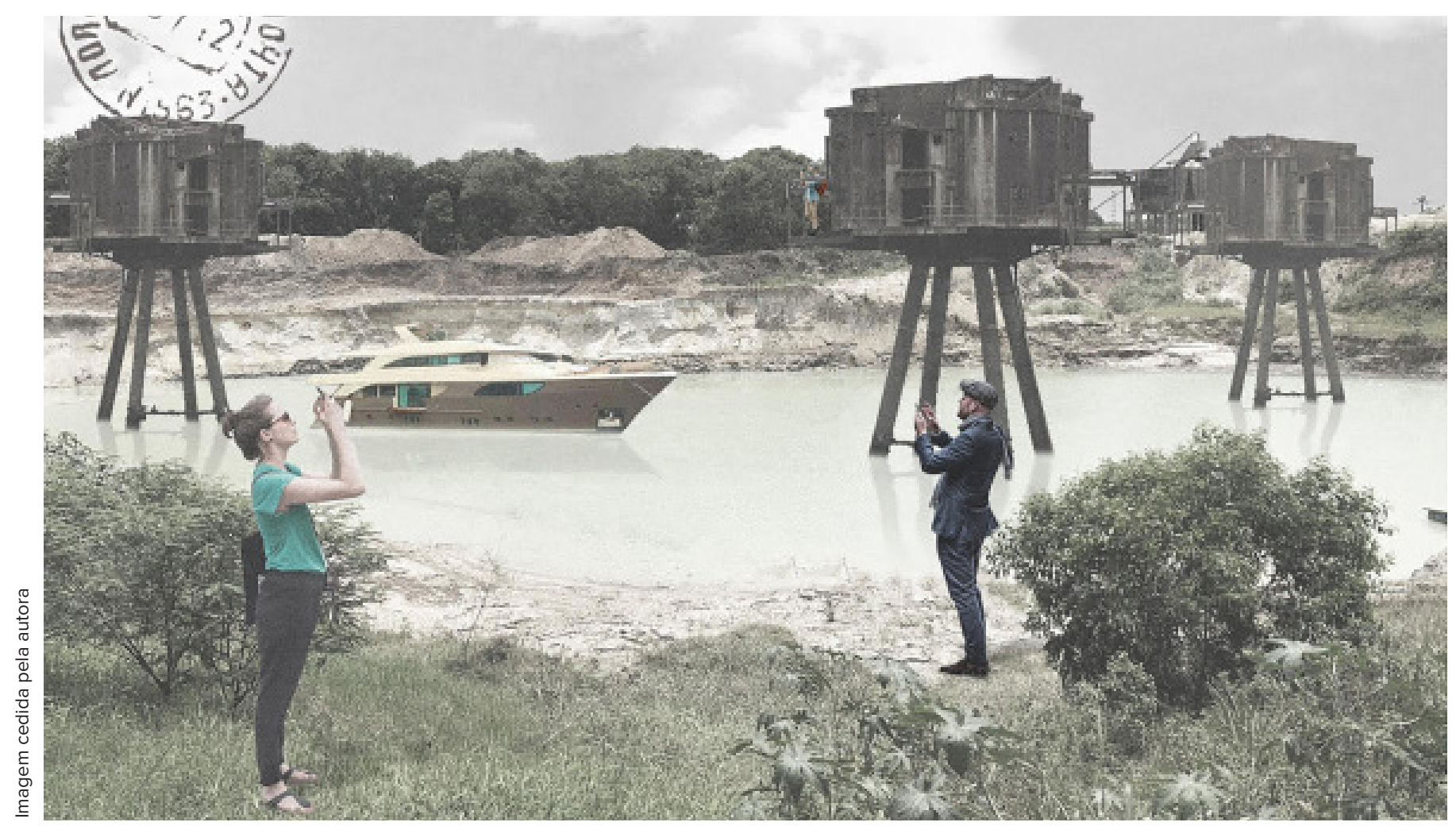

Colagem com a proposta de intervenção, produzida pelo Grupo 3.

Revista online do Departamento de Arquitetura e Urbanismo da Pontifícia Universidade Católica

Puc-Rio - Rio de Janeiro Brasil

Ano $5-N^{\circ} 8$ - ISSN 2446-7340 


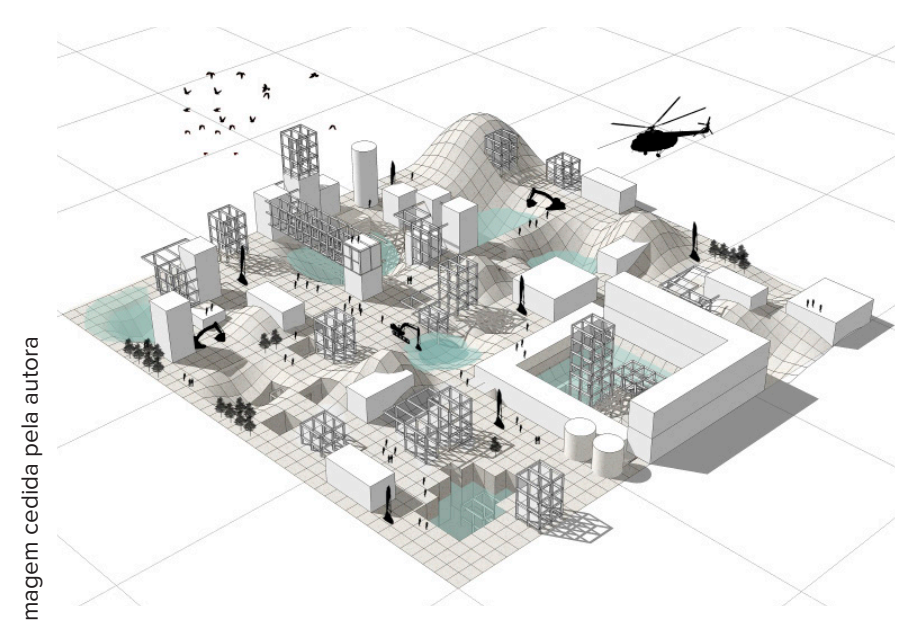

Perspectiva isométrica do cenário proposto, produzida pelo Grupo 4.

\section{Conclusáo}

As propostas desenvolvidas após a visita, palestras e discussôes em grupo foram apresentadas no campus $\mathrm{da}$ PUC-Rio, durante um evento aberto que deu início à nona Semana de Arquitetura e Urbanismo da Universidade. Arquitetos e estudantes explicaram motivaçôes que impulsionaram cada projeto e juntos questionaram a participação da arquitetura e da construção civil em um processo tão danoso para a população, a paisagem e o território de Itaguaí e do raio metropolitano do Rio de Janeiro, direta ou indiretamente.

O fazer urbano posto em questão ressalta como a construção traz consequências para a própria vida, como ambiente ecológico e como condiçóes de trabalho, especialmente num país como o Brasil que possui metrópoles infladas e uma larga política de cidades planejadas. Por isso, é necessário levantar de certa forma os meios e relaçóes que possibilitam e repetem a ideia de "progresso" atrelada ao mercado imobiliário.

Para todos os grupos prevaleceu o caráter utópico das iniciativas que, de certa forma, ressalta o contexto quase fictício de um areal, ainda que cada proposta tenha uma direçáo específica de questionamento so- bre o sistema de extração. Nesse sentido, entende-se a dependência da atividade extrativista e, por isso, a escolha pelo absurdo como forma de destacar o processo e dar luz aos aspectos violentos e velados que a sustentam.

\section{Notas de fim:}

1. Grupo 01 formado por: Gabriel Martucci (UFRJ), Julia Maria Bethlem (PUC-Rio), Julia Pinho (PUC-Rio), Michel Zalis (PUC-Rio), Ricardo Kranen (UFRJ) e os arquitetos André Velloso (ArqBr), Cauê Capillé e Luísa Bogossian (Estúdio Guanabara).

2. Grupo 02 formado por: Beatriz Carneiro (PUC-Rio), Bruno Bins (PUC-Rio), Gabriel Nigri (UFRJ), José Luis da Costa (PUC-Rio), Mateus Leoni (PUC-Rio), Yasmin Anefalos (UFRJ) e os arquitetos André Cavendish (GRU.A) e Juliana Sicuro (OCO).

3. Grupo 03 formado por: Julia Daher (UFRJ), Larissa Lima (PUC-Rio), Leonardo Filippo (PUC-Rio), Letícia Nasser (PUC-Rio), Mariana Maciel (UFRJ), Thaís Aquino (PUC-Rio) e os arquitetos Rodrigo Bocater (RVBA Arquitetos) e Vitor Garcez (OCO).

4. Grupo 04 formado por: Antonio Machado (UFRJ), Federica Linares (PUC-Rio), Julia Rittscher (PUC-Rio), Maria Vitória Martins (PUC-Rio), Pedro Brito (PUCRio), Renata Lopes (PUC-Rio) e os arquitetos Caio Calafate (GRU.A), Danilo Filgueiras (Estúdio Guanabara) e Pedro Varella (GRU.A).

\section{Referências Bibliográficas}

WISNIK, Guilherme. Dentro do Nevoeiro: arquitetura, arte e tecnologia contemporâneas. São Paulo: UBU Editora, 2018. 
Revista online do Departamento de Arquitetura e Urbanismo da Pontifícia Universidade Católica Puc-Rio - Rio de Janeiro Brasil

Ano $5-N^{\circ} 8$ - ISSN 2446-7340 
Revista online do Departamento de Arquitetura e Urbanismo da Pontifícia Universidade Católica Puc-Rio - Rio de Janeiro Brasil

Ano $5-N^{\circ} 8$ - ISSN 2446-7340 
Revista online do Departamento de Arquitetura e Urbanismo da Pontifícia Universidade Católica Puc-Rio - Rio de Janeiro Brasil

Ano $5-N^{\circ} 8$ - ISSN 2446-7340 
Revista online do Departamento de Arquitetura e Urbanismo da Pontifícia Universidade Católica Puc-Rio - Rio de Janeiro Brasil

Ano $5-N^{\circ} 8$ - ISSN 2446-7340 